\title{
Role of Maternal Serum Glycodelin as Predictor of Ectopic Pregnancy in First Trimester
}

\author{
Wasan Wajdi Ibrahim ${ }^{1}$, Afraa Mahjoob Al-Naddawi' ${ }^{1}$ Hayder A. Fawzi ${ }^{2^{*}}$
}

\begin{abstract}
Objectives: Assessment of glycodelin (GD) as a marker for unruptured ectopic pregnancy (EP) in the first trimester of pregnancy. Materials and Methods: This case-control study was conducted during June 2016 to May 2017 in the Obstetrics and Gynecological Department of Baghdad University at Baghdad teaching hospital/medical city complex. In this study, 100 pregnant women in their first trimester of pregnancy were included after clinical and ultrasonic findings.

Results: Based on the results, GD levels in EP were significantly lower than those with normal intrauterine pregnancy $(1.58 \pm 1.18$ vs. $30.1 \pm 11.9$ ). In addition, using receiver operator curve analysis, the cut-off GD level of 9.5 and less had acceptable validity results (100\% sensitivity, $100 \%$ specificity, $95 \%$ positive predictive value, $100 \%$ negative predictive value, and accuracy $100 \%$ ) to predict EP. Conclusions: In general, serum GD is considered as an excellent predictor of unruptured EP.

Keywords: Abdominal pain, Ectopic pregnancy, Glycodelin, Vaginal bleeding
\end{abstract}

\section{Introduction}

The term "ectopic pregnancy" (EP) comes from the word ektopos which means "out of place" (1), indicating the implantation of the blastocysts outside of the uterine cavity endometrium since the majority of them are implanted in the fallopian tube in which the embryo ceases growing (2). In addition, EP is considered as the major cause of maternal mortality and morbidity (3).

Glycodelin (GD) is a glycoprotein that is primarily expressed in the tissues of reproductive organs., During human pregnancy, GD peaks at first trimester of pregnancy. GD has several glycoforms (e.g., A, S, F, \& C), some of which are regulated by progesterone, while others act as the inhibitors on sperm motility (i.e., oocyte binding), as well as immunosuppression and immunomodulation actions, indicating the role of GD in fertilization and implantation (4). The current work aimed to assess the use of GD as a potential marker for predicting EP.

\footnotetext{
Materials and Methods

Study Design

The present case-control study was performed from the first of June 2016 to the 30th of May 2017 in the Obstetrics and Gynecology Department of Baghdad University at Baghdad teaching hospital/medical city complex. One hundred pregnant women in the first trimester of pregnancy were included in this study. After clinical and ultrasonic findings, they were divided into 2 groups including those with unruptured EP (50 cases) and normal intrauterine pregnancy (50 controls).
}

\section{Data Collection}

Socio-demographic information was collected about age, gestational age (GA), obstetrical history, past medical and surgical history, and previous mode of delivery. In addition, trans-abdominal ultrasound was performed by ultrasound machine (Philips HD 11XE) using the curvilinear probe (frequency 2-5MHZ).

\section{Laboratory Analysis}

To this end, $5 \mathrm{~mL}$ of blood was taken from the patient and control groups to measure the serum GD and then the serum was separated and stored at $-20^{\circ} \mathrm{C}$ or $-80^{\circ} \mathrm{C}$ after centrifugation for 15 minutes. Finally, the sera were assayed using the human GD Elisa kit (catalog number. SB-E12071h) for the quantitative determination of human GD concentration in the serum.

\section{Statistical Analysis}

Independent $t$ test and chi-square test were used for the statistical inference between EP and intrauterine pregnancy (IUP) groups. Additionally, receiver operator curve analysis was utilized to determine the area under the curve, the cut-off, and its validity. All analyses were performed using SPSS 21.0 software (Chicago, IL) and $P<0.05$ was considered statistically significant.

\section{Results}

A total of 100 pregnant women in early pregnancy were included in this study. Based on the results, no significant difference was observed in age, gravidity, 
parity, miscarriage, past medical and surgical history, and previous mode of delivery while GA was significantly lower in an EP (Table 1).

Similarly, GD levels in EP were significantly lower than those with normal IUP $(1.58 \pm 1.18$ vs. $30.1 \pm 11.9)$, and these lower levels were maintained in different GAs (i.e., $6^{\text {th }}, 7^{\text {th }}$, and $8^{\text {th }}$ weeks). The results further revealed that in EP, an increased in GA led to a decrease in GD levels while in normal pregnancy, GD levels increased with an increase in GA (Table 2 and Figure 1).

Moreover, receiver operator characteristic analysis was performed to assess the validity of GD as the predictor of EP. Eventually, GD was found to be an excellent predictor of EP with an optimal cut point of $<9.5 \mathrm{ng} / \mathrm{mL}$ for predicting EP with 100\% sensitivity, 100\% specificity, 95\% positive predictive value, $100 \%$ negative predictive value, and $100 \%$ accuracy (Table 3 ).

\section{Discussion}

EP is still regarded as one of the important causes of

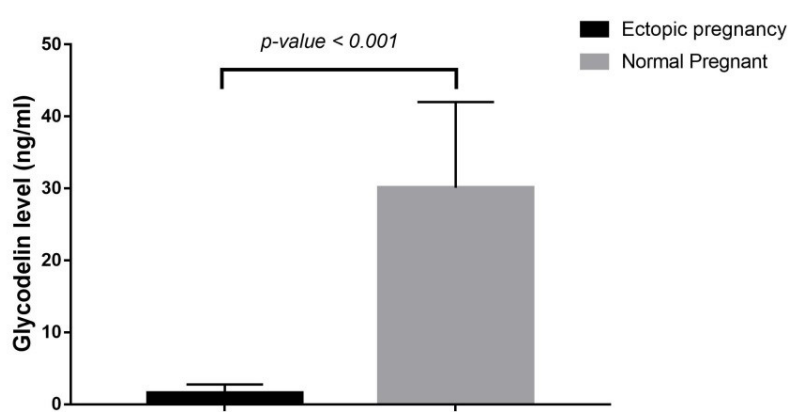

Figure 1. Glycodelin Serum Level According to Study Groups.

maternal death worldwide although mortality has simultaneously declined from 35 deaths/10000 EPs in 1970 to 4 deaths/10000 EPs in 1985 (5). In the United Kingdom, the number of ectopics and deaths has been fixed in the last 12 years with the mortality rate at 4 per 10000 maternal pregnancies (6).

In the current study, serum GD (previously named

Table 1. Assessment of Demographic and Clinical Characteristics in Ectopic and Normal Pregnancy

\begin{tabular}{|c|c|c|c|}
\hline Variables & Ectopic Pregnancy & Normal Pregnancy & $P$ Value \\
\hline Age $(y)$, mean \pm SD & $28.6 \pm 7$ & $28.2 \pm 5.7$ & 0.755 \\
\hline Gravidity, mean \pm SD & $4.1 \pm 2$ & $4.4 \pm 1.6$ & 0.410 \\
\hline Parity, mean \pm SD & $2.2 \pm 1.4$ & $2.3 \pm 1.1$ & 0.692 \\
\hline \multicolumn{4}{|l|}{ Miscarriage, No. (\%) } \\
\hline No & $25(50)$ & $21(42)$ & \multirow{3}{*}{0.600} \\
\hline $1-2$ & $20(40)$ & $22(44)$ & \\
\hline$\geq 3$ & $5(10)$ & $7(14)$ & \\
\hline Gestational age (wk), mean \pm SD & $6.6 \pm 0.5$ & $7.4 \pm 0.5$ & $<0.001$ \\
\hline \multicolumn{4}{|l|}{ Gestational age, No. (\%) } \\
\hline $6^{\text {th }}$ week & $19(38)$ & $0(0)$ & \multirow{3}{*}{$<0.001$} \\
\hline $7^{\text {th }}$ week & $29(58)$ & $30(60)$ & \\
\hline $8^{\text {th }}$ week & $2(4)$ & $20(40)$ & \\
\hline Positive past-medical and surgical history, No. (\%) & $11(22)$ & $14(28)$ & 0.400 \\
\hline \multicolumn{4}{|l|}{ Previous mode of delivery, No. (\%) } \\
\hline Vaginal & $26(52)$ & $28(56)$ & \multirow[t]{2}{*}{0.600} \\
\hline Caesarean section & $24(48)$ & $22(44)$ & \\
\hline
\end{tabular}

Abbreviation: SD, standard deviation.

Table 2. Assessment of Glycodelin Levels in All Patients and According to Gestational Age

\begin{tabular}{|c|c|c|c|}
\hline Variables & Ectopic Pregnancy & Normal Pregnancy & $P$ Value \\
\hline Glycodelin level (ng/mL) & $1.58 \pm 1.18$ & $30.1 \pm 11.9$ & $<0.001$ \\
\hline \multicolumn{4}{|c|}{ Glycodelin level $(\mathrm{ng} / \mathrm{mL})$ by gestational age, mean $\pm \mathrm{SD}$} \\
\hline $6^{\text {th }}$ week & $3.03 \pm 1.3$ & $9.52 \pm 3.8$ & $<0.001$ \\
\hline $7^{\text {th }}$ week & $1.21 \pm 0.9$ & $20.30 \pm 11.2$ & $<0.001$ \\
\hline $8^{\text {th }}$ week & $0.34 \pm 0.16$ & $47.01 \pm 23.4$ & $<0.001$ \\
\hline
\end{tabular}

Abbreviation: SD, standard deviation.

Table 3. ROC Analysis of Glycodelin as a Predictor of Ectopic Pregnancy

\begin{tabular}{lccccccc}
\hline Cut-off point & AUC & P-value & Sensitivity & Specificity & PPV & NPV \\
\hline$<9.5$ & 1.0 & $<0.001$ & $100 \%$ & $100 \%$ & $95 \%$ & $100 \%$ & $100 \%$ \\
\hline
\end{tabular}

Abbreviations: AUC, area under the curve; PPV, positive predictive value; NPV, negative predictive value; ROC, receiver operating characteristic. 
as placental protein 14) was significantly lower in EP compared to normal pregnancy $(1.58 \pm 1.18$ vs. $30.1 \pm$ $11.9 \mathrm{ng} / \mathrm{mL}$, respectively) these findings were consistent through sixth, seventh, and eighth of pregnancy. Further analysis using the receiver operator curve demonstrated that test serum GD at the cut-off of $\leq 9.5 \mathrm{ng} / \mathrm{mL}$ had an excellent ability to predict EP with $100 \%$ sensitivity and $100 \%$ specificity, which is in agreement with the findings of Pedersen and Ruge (7). The results of another study showed that the GD level was low $(<5$ th percentile of the reference range of GD) in $81 \%$ of women with EP (8). In addition, several other studies reported similar findings such as Ruge et al (9) and Foth \& Römer who studied 169 women in their first trimester and found that GD serum level was significantly lower compared to normal pregnancy and those with incomplete abortion (10). In a more recent study that examined multiple markers for predicting EP in the first trimester, GD was reported as the best individual marker of extra-uterine location (AUC 0.61 ) and further analysis at the cut-pint of $\leq 1.39 \mathrm{ng} /$ mL GD had higher sensitivity to predict EP; this study showed the clear role of GD as a screening marker for EP, especially when incorporated with other biomarkers (11). The findings of all these studies are in line with the results of the current study, indicating that serum GD was significantly lower in EP compared to normal pregnancy.

In the current study, GD levels had an inverse relationship with GA, namely, it decreased with advanced GA (3.03 \pm $1.3,1.21 \pm 0.9$, and $0.34 \pm 0.16$ from sixth to eighth weeks of GA) while the relationship was direct between GA and GD levels in a normal pregnancy. Foth and Römer (10) revealed that the level of GD decreases with increasing GA in the first trimester of the ectopic patients, which corroborates with the findings of the present study.

Currently, no single biomarker for EP has yielded sufficient diagnostic accuracy and good reproducible results. Generally speaking, the makers of normal trophoblast and decidual function are usually lower in EP compared to normal IUP (12). In a normal pregnancy, the GD level increases as pregnancy progresses until 8-10 weeks of gestation; this can be attributed to the hormonal effect in this period of pregnancy, a procedure which is done by the corpus luteum (13). In ectopic pregnancies, the low GD levels might be a consequence of abnormalities in the functions of the corpus luteum (14).

\section{Limitation of the Study}

Small sample size within a short period of the study, singlecenter for research, the absence of temporal relationship, and selection bias were among the limitations of the current study.

\section{Conclusions}

Overall, the serum level of GD significantly decreased in the first trimester of EP while in normal pregnancy, it steadily increased the validity results of GD (i.e., $100 \%$ sensitivity, $100 \%$ specificity, $95 \%$ positive predictive value, $100 \%$ negative predictive value, and accuracy $100 \%$ ) in the prediction of EP at the cut point of $9.5 \mathrm{ng} / \mathrm{mL}$.

\section{Conflict of Interests}

Authors declare that they have no conflict of interests.

\section{Ethical Issues}

The study was approved by the local committee in the Iraqi Ministry of Health, the Council of Arab Board of Health Specialization. The purpose and procedures were explained to all women, and they were given the right to participate in the study Then, written informed consent was taken with the reassurance that obtained interpretation would be kept confidential and not be used for another research object, in accordance with the Declaration of Helsinki (as revised in Edinburgh, 2000).

\section{Financial Support}

None.

\section{References}

1. Kirk E, Bourne T. Ectopic pregnancy. Obstet Gynaecol Reprod Med. 2011;21(7):207-211. doi:10.1016/j. ogrm.2011.04.003

2. Sivalingam VN, Duncan WC, Kirk E, Shephard LA, Horne AW. Diagnosis and management of ectopic pregnancy. J Fam Plann Reprod Health Care. 2011;37(4):231-240. doi:10.1136/jfprhc-2011-0073

3. Crochet JR, Bastian LA, Chireau MV. Does this woman have an ectopic pregnancy?: the rational clinical examination systematic review. JAMA. 2013;309(16):1722-1729. doi:10.1001/jama.2013.3914

4. Uchida H, Maruyama T, Nishikawa-Uchida S, Miyazaki K, Masuda H, Yoshimura Y. Glycodelin in reproduction. Reprod Med Biol. 2013;12(3):79-84. doi:10.1007/s12522013-0144-2

5. DeCherney AH, Agel WO. Ectopic Pregnancy. The Global Library of Women's Medicine; 2008. doi:10.3843/ GLOWM.10047

6. Tay JI, Moore J, Walker JJ. Ectopic pregnancy. West J Med. 2000;173(2):131-134. doi:10.1136/ewjm.173.2.131

7. Pedersen JF, Ruge S. Serum level of secretory endometrial protein PP-14 in intact ectopic pregnancy. Br J Obstet Gynaecol. 1991;98(4):414. doi:10.1111/j.1471-0528.1991. tb13438.x

8. Stabile I, Olajide F, Chard T, Grudzinskas JG. Circulating levels of placental protein 14 in ectopic pregnancy. Br J Obstet Gynaecol. 1994;101(9):762-764. doi:10.1111/j.1471-0528.1994.tb11942.x

9. Ruge S, Sørensen S, Vejtorp M, Vejerslev LO. The secretory endometrial protein, placental protein 14, in women with ectopic gestation. Fertil Steril. 1992;57(1):102-106. doi:10.1016/s0015-0282(16)54784-0

10. Foth D, Römer T. Glycodelin serum levels in women with ectopic pregnancy. Eur J Obstet Gynecol Reprod Biol. 2003;108(2):199-202. doi:10.1016/s0301-2115(02)00437-2 
11. Senapati S, Sammel MD, Butts SF, Takacs P, Chung $\mathrm{K}$, Barnhart KT. Predicting first trimester pregnancy outcome: derivation of a multiple marker test. Fertil Steril. 2016;106(7):1725-1732.e1723. doi:10.1016/j. fertnstert.2016.08.044

12. Cartwright J, Duncan WC, Critchley HO, Horne AW. Serum biomarkers of tubal ectopic pregnancy: current candidates and future possibilities. Reproduction. 2009;138(1):9-22. doi:10.1530/rep-09-0060
13. Seppälä M, Koistinen H, Koistinen R. Glycodelins. Trends Endocrinol Metab. 2001;12(3):111-117. doi:10.1016/S10432760(00)00365-9

14. Critchley HO, Chard T, Lieberman BA, Buckley $\mathrm{CH}$, Anderson DC. Serum PP14 levels in a patient with Turner's syndrome pregnant after frozen embryo transfer. Hum Reprod. 1990;5(3):250-254. doi:10.1093/oxfordjournals. humrep.a137082

(C) 2019 The Author (s); This is an open-access article distributed under the terms of the Creative Commons Attribution License (http://creativecommons.org/licenses/by/4.0), which permits unrestricted use, distribution, and reproduction in any medium, provided the original work is properly cited. 